\title{
The elementary school teachers' ability in adding and subtracting fraction, and interpreting and computing multiplication and division fraction
}

\author{
Hongki Julie \\ Mathematics Education Department, Sanata Dharma University \\ hongkijulie@yahoo.co.id
}

\begin{abstract}
The purpose of this study was to describe the elementary school teachers' mathematical skills on the numbers, especially fractions after they have participated in a workshop. The teachers' abilities which would be described by the researcher in this study were the ability to interpret, to order, to add and subtract, to interpret the meaning of the multiplication and division, to multiply and divide, and to make problems about fractions. In this paper, the author just only would describe the teachers' mathematical skills in adding and subtracting two fractions, interpreting the multiplication and division of two fractions, multiplying and dividing two fractions. This capability was described base on the results of a test given to teachers after they have attended the workshop. Research subjects in this study were 17 Kanisius Demangan elementary school teachers at Yogyakarta. Of the 17 teachers, 16 teachers could add and subtract two fractions. Six teachers of 17 teachers could interpret what was the meaning of multiplication of two fractions. One teacher could interpret what was the meaning of division of two fractions. All of the teachers could divide two fractions. Sixteen teachers of 17 teachers could multiply two fractions.
\end{abstract}

\section{Introduction}

In 2002, Sutarto Hadi developed a professional development model for the junior high school teacher. The model was developed in his study as follows:

a. To conduct workshops for junior high school teachers who would be the subject of the research.

b. To conduct classroom practice.

c. To make a reflection.

From his research, he concluded that the development model of teacher professionalism developed in this study was a good model for the professional development of mathematics teachers in Indonesia, particular to introduce a new approach to teaching mathematics.

Kanisius Demangan elementary school want to improve the quality of their teachers' ability in mathematics. Based on the research results of Sutarto Hadi (2002), the effort which was made by the researcher to improve the mathematical skills of teachers in Kanisius Demangan elementary school was to provide mathematics workshops for teachers in that school.Teachers'math skills which would be upgraded in this research were divided into four areas, namely: numbers, geometry, measurement, and statistics. The study's result would be presented was the teachers' ability in numbers, especially in 
adding and subtracting fraction, and interpreting and computing multiplication and division fraction.

According to Patricia F. Campbell et al. (2014), mathematical skills and pedagogy abilities of primary teachers were directly and positively related to achievement of students taught by them. There was a significant relationship between the teachers' perception with the knowledge achieved by the students. The teachers' perception in this study was defined as (1) the teachers' paradigm on the mathematics teaching and learning process, and (2) teachers' care to the tendency of students' math skills. Teachers' care to the tendency of students' mathematical skills related to the mathematical knowledge of teachers. Teachers' paradigm on the settlement of mathematical models and learning organization supported teacher mastery of the mathematics knowledge and the pedagogy. Therefore to improve students achievement, the teachers' mathematical abilities were needed to be enhanced.

According to Neisser, 1967 (in Solso 1991), the term of cognition refers to the entire process in which the sensory input was changed, reduced, interpreted, stored, retrieved and used. According to Matlin (2009), the term of cognition referred to the process of receiving, storing, changes, and using of knowledge. According to Marpaung (1987), cognition was defined as something that is internal: something that could not be observed directly. According to Marpaung (1987), the cognition process meant a process what was going on in one's mind from receiving the data, then processing it, storing in the form of information in memory, and recalling from memory when needed to further data processing. So, the cognitive process was a process that occurs in a person's mind when they accepted and processed data, stored information in memory and recalled from memory when it needed to further data processing and cognition was information held by a person in his or her mind about something.

Skemp (2009) argued that mathematics was how to use the human mind that would increase the power of the human way of thinking. Therefore, according to Skemp (2009), the mathematics should be taught in ways that allow students to use their intelligence and not just rote learning. According to Skemp (2009), there were two principles that need to be considered in the study mathematics, namely:

a. The mathematics concept on a higher level could not be communicated to the students by definition but it was needed to provide samples.

b. The students need to form a concept in their mind that will be used to understand advance mathematics.

Lortie-Forgues, Tian and Siegel (2015) suggested that students' understanding of the fractions was very important to study of mathematics further and was also used in many professions, but many students had great difficulties in understanding it. Furthermore, according to Ma (1999), the difficulty was not only the difficulties experienced by students in learning fractions, but also the difficulties experienced teachers to teach the concept of fraction.

There were several studies that have been done related to fractions and the studies showed that students had some difficulties to understand fractions. According to Lamon (2001, in Ayunika, 2012), the development of the students' understanding to the 
meaning of fractions in the teaching-learning process was a complex process because the concept of fraction had a number of interpretations, namely (1) fraction as a part of the whole, (2) fraction as the result of a measurement, (3) fraction as an operator, (4) fraction as a quotient, and (5) fraction as a ratio. According to Ross and Case (1999 in Shanty, 2011), on the teaching - learning process about fractions, teachers often emphasized on how to do the operation procedure than on the meaning of operation. Stafylidou and Vosniadou (2004 in Shanty, 2011) stated that one of the reasons why the mathematical idea of fractions was systematically misinterpreted by students was an inconsistency with the principles of arithmetic used in operations involving natural numbers. For example in the multiplication of natural numbers, if the two natural numbers multiplied, then the multiplicative result was a natural number greater than or equal to two natural numbers were multiplied. It was not always the case if the two fractions were multiplied. According to Streefland (1991), in many textbooks the instruction of fractions was characterized by (1) Towards the concept of fraction; (2) There were not meaningful contexts both as sources and domains for the application of the fractions; (3) The isolated use of models and patterns, which never extends to serve the process of algorithmization or mathematization; (4) There were not connections with mathematical domains, such as decimal fractions, ratios, scale, and percentages (Vergnaud, 1981); and (5) Towards the algorithms.

The purpose of this study was to describe the elementary school teachers' mathematical skills on the numbers, especially fractions after they have participated in the workshops. The abilities of teachers would be described in this study were the ability to interpret a fraction, to order some fractions, to add and subtract two fractions, to interpret the multiplication and division of two fractions, and to multiply and divide two fractions. In this paper, the author just only would make description about the teachers' mathematical skills in adding and subtracting fraction, and interpreting and computing multiplication and division fraction. This capability was described by the author base on the results of a test given to teachers after they have attended the workshop.

The material presented in this workshop was about interpreting and ordering fractions as follows:

a. The definition of addition and subtraction on fractions.

b. The adding and subtracting technique, i.e. by equating the denominator of the fractions were added and subtracted.

c. The characteristic of addition and subtraction on fractions.

d. The definition of multiplication on fractions.

e. The characteristic of multiplication on fractions.

f. The definition of division on fractions.

g. The characteristic of division on fractions.

\section{Research Methodology}

The type of this study was the qualitative study because this study seeks to describe a phenomenon that occurs in a natural situation, i.e. the teachers' mathematics ability to add and subtract of fraction, and interprete and compute multiplication and division of 
fraction after they followed the workshop. There were 17 teachers who became subjects in this research. In general, the steps were carried out by the researcher in building teachers' ability profiles above were as follows:

a. The researcher held a workshop about adding and subtracting fraction, and interpreting and computing multiplication and division fraction.

b. The researcher made two problems about adding and subtracting fraction, and interpreting and computing multiplication and division fraction which were done by the teachers after they attended a workshop, i.e.

1)Explain how do you add and subtract $\frac{7}{8}$ and $\frac{2}{3}$ and compute it! The indicators of the first question were the teacher could explain what the adding and subtracting fraction procedure and the teacher could add and subtract fractions.

2)Explain what does the meaning of $\frac{1}{3} \times \frac{5}{2}$ and $\frac{5}{6}: \frac{1}{3}$ ! Explain how do you multiply and divide two fractions and compute it! The indicators of the second question were the teacher could explain what the meaning of multiplying and dividing fractions, the teacher could explain what the procedure of multiplying and dividing fractions, and the teacher could multiply and divide fractions.

c. The researcher made the description about the material presented in the workshop on adding and subtracting fraction, and interpreting and computing multiplication and division fraction.

d. The researcher made a description of how the process of the workshop happens.

e. The researcher described the teachers' mathematics ability profiles on adding and subtracting fraction, and interpreting and computing multiplication and division fraction.

Activities that occur in the workshop were as follows:

a. The facilitator asked to workshop participants what was the definition of addition and subtraction on fractions .

b. None of the participants were able to answer the question.

c. The facilitator asked the participants what techniques were used to add and subtract two fractions.

d. A participant explained how to add and subtract two fractions by equating the denominator of the fractions that will be added or subtracted.

e. The facilitator provided reinforcement about how to add and subtract two fractions and what was the definition of the adding and subtracting fractions.

f. The facilitator asked participants what were the properties of addition and subtraction on fractions.

g. A participant said, the properties of the addition of fractions were commutative, associative and distributive.

h. Other participant said, the property of the fractional subtraction was distributive.

i. The facilitator provides reinforcement about the addition and subtraction properties.

j. The facilitator asked the participants what the meaning of fractional multiplication and how to multiply two fractions.

k. A participant said, multiplying two fractions meant multiplied numerator by numerator and denominator multiplied by the denominator.

1. The facilitator provided reinforcement as follows: $\frac{a}{c} \times \frac{b}{d}=\frac{a \times b}{c \times d}$ and $\frac{a}{c} \times \frac{b}{d}$ represented $\frac{a}{c}$ part of $\frac{b}{d}$.

$\mathrm{m}$. The facilitator asked the participants what properties of fraction multiplication. 
n. One of the participants said the multiplication fraction properties were commutative and associative.

o. The facilitator provided reinforcement to participants about the properties of the fractional multiplication operation were commutative and associative

p. The facilitator asked the participants what was the definition of the fractional division.

q. A participant answered how to divide two fractions, namely by changing to the multiplication first. After that, the two fractions were multiplied.

r. The facilitator provided reinforcement to the participants as follows: Asume that $\frac{a}{c}$, and $\frac{b}{d}$ were arbitrary fractions, a sharing out by $\mathrm{b}$, and c sharing out by $\mathrm{d}$, then the fractional division definition was as follows: $\frac{a}{c}: \frac{b}{d}=\frac{a: b}{c: d} \cdot \frac{a}{c}: \frac{b}{d}$ represented how many $\frac{b}{d}$ on $\frac{a}{c}$.

s. The facilitator asked the participants, what the property of the fractional division.

t. None of the participants answered it.

$\mathrm{u}$. The facilitator emphasized that what was expressed by participants in advance about how to divide two fractions was the property of the division of fractions, i.e. $\frac{a}{c}: \frac{b}{d}=\frac{a}{c} \times \frac{d}{b}=\frac{a \times d}{c \times b}$.

\section{Result and Discussion}

The teachers' answer for the question how do you add and subtract $\frac{7}{8}$ and $\frac{2}{3}$ and how do you compute it were

a. The way of add and subtract two fractions was as follows:

1) 16 teachers answered that two fractions could be added or subtracted by equating the denominator of the fractions that will be added or subtracted (look figure 1).

2) There was one teacher who did not answer the question.

b. 16 teachers did the addition process of $\frac{7}{8}$ and $\frac{2}{3}$ as follows: $\frac{7}{8}+\frac{2}{3}=\frac{21}{24}+\frac{16}{24}=\frac{37}{24}$ (look figure 2).

c. 16 teachers did the subtraction process of $\frac{7}{8}$ and $\frac{2}{3}$ as follows: $\frac{7}{8}-\frac{2}{3}=\frac{21}{24}-\frac{16}{24}=$ $\frac{5}{24}$ (look figure 2 ).
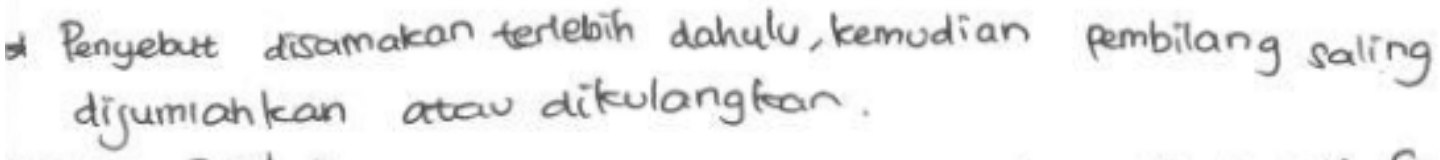

Figure 1. The example of the teacher answer for the question how do you add and

$$
\text { subtract } \frac{7}{8} \text { and } \frac{2}{3}
$$




$$
\begin{aligned}
& \text { (1) } \frac{7}{8}+\frac{2}{3}=\frac{21+16}{24}=\frac{37}{24}=1 \frac{13}{24} \\
& \text { (2) } \frac{7}{8}-\frac{2}{3}=\frac{21-16}{24}=\frac{5}{24} .
\end{aligned}
$$

Figure 2. The example of the teacher answer for the question how do you compute the

$$
\text { addition and the substraction of } \frac{7}{8} \text { and } \frac{2}{3}
$$

The teachers' answer for the question what the meaning of $\frac{1}{3} \times \frac{5}{2}$ and $\frac{5}{6}: \frac{1}{3}$ and how do you multiply and divide it were

a. Six teachers answered that the meaning of $\frac{1}{3} \times \frac{5}{2}$ was $\frac{1}{3}$ part of $\frac{5}{2}$ (look figure 3 ).

b. One teacher answered that the meaning of $\frac{5}{6}: \frac{1}{3}$ was how many fraction $\frac{1}{3}$ on fraction $\frac{5}{6}$.

c. Two teachers answered that the meaning of $\frac{5}{6}: \frac{1}{3}$ was $\frac{5}{6}$ part of $\frac{1}{3}$.

d. One teacher answered that the meaning of $\frac{5}{6}: \frac{1}{3}$ was $\frac{5}{6}$ part divided by $\frac{1}{3}$ part (look figure 3).

e. 16 teachers answered $\frac{1}{3} \times \frac{5}{2}=\frac{1 \times 5}{3 \times 2}=\frac{5}{6}$ (look figure 3 ).

f. One teacher answered $\frac{1}{3} \times \frac{5}{2}=\frac{5}{10}$.

g. 17 teachers answered $\frac{5}{6}: \frac{1}{3}=\frac{5}{6} \times \frac{3}{1}=\frac{15}{6}=\frac{5}{2}($ look figure 3$)$.

$$
\text { Jawab: } \begin{aligned}
+\frac{1}{3} \times \frac{5}{2} \Rightarrow \frac{1}{3} \text { bagian dari } \frac{5}{2}=2 \frac{1}{2} \\
\frac{1}{3} \times \frac{5}{2}=\frac{1 \times 5}{3 \times 2}=\frac{5}{6} \\
+\frac{5}{6}: \frac{1}{3} \Rightarrow \frac{5}{6} \text { bagian dibasi } \frac{1}{3} / \frac{1}{3} \text { basian dari } \frac{5}{6} \\
\frac{5}{6}: \frac{1}{3}=\frac{5: 1}{6: 3}=\frac{5}{2} \\
\frac{5}{6}: \frac{1}{3}=\frac{5}{6} \times \frac{5}{1}=\frac{15}{6}=\frac{5}{2}=2 \frac{1}{2} \\
=\frac{5}{2}
\end{aligned}
$$

Figure 3. The example of the teacher answer for the question what does the meaning of $\frac{1}{3} \times \frac{5}{2}$ and $\frac{5}{6}: \frac{1}{3}$ and how do you multiply and divide two fractions

The teachers' mathematics ability profiles on adding and subtracting fractions, and interpreting and computing multiplication and division fractions from this research as follows:

a. 16 teachers of 17 teachers had the ability to explain how to add and subtract two fractions.

b. 16 teachers of 17 teachers had the ability to add and subtract two fractions. 
c. Six teachers of 17 teachers had the ability to explain the meaning of multiplying two fractions.

d. One teacher of 17 teachers had the ability to explain the meaning of dividing two fractions.

e. 16 teachers of 17 teachers had the ability to multiply two fractions.

f. All of teachers had the ability to divide two fractions.

From the teachers' mathematics ability profiles, the researcher got a description of the teachers' mathematics ability on adding and subtracting fractions, and interpreting and computing multiplication and division fractions. The mathematics ability of teachers to calculate addition, subtraction, multiplication, and division of fractions was good. The mathematics ability of teachers that really needs to be improved was the mathematics ability of teachers to interpret multiplication and division of two fractions. From these profiles, the researcher could suspect that the tendency of the learning process for fractions was mechanistic, because the mathematical abilities of teachers were good only on the mechanistic. If the school wants to change the tendency of the learning process for fractions to conceptual, then the school need to do is improve the mathematics ability of teachers to interpret multiplication and division of two fractions.

\section{Conclusions}

There were two conclusions obtained from this research process related to the ability profile of teachers in adding and subtracting fractions, and interpreting and computing multiplication and division fractions, namely:

a. The ability of dividing two fractions was the ability of the most widely held by teachers.

b. Teachers' understanding of the meaning of multiplication and division of fractions still needs to be improved because only six teachers who had the ability to interpret the multiplication of fractions and two teachers who had the ability to interpret the division of fractions.

\section{References}

[1] Ayunika, El. P. S., Juniati, D., \& Maesuri, S. P. (2012). Early fractions learning of $3^{\text {rd }}$-grade students in SD Laboratorium Unesa. IndoMS Journal Mathematics Education, 3, 17-28

[2] Campbell, Patricia F., dkk. 2014. The Relationship Between Teachers' Mathematical Content and Pedagogical Knowledge, Teachers' Perceptions, and Student Achievement. Journal for Research in Mathematics Education, Volume 45, No. 4, pp. 419 - 459.

[3] Cochran, K. F., King, R. A., \& De Ruiter, J. A. 1991. Pedagogical Content Knowledge: A Tentative Model for Teacher Preparation. Symposium paper presented at the annual meeting of the American Educational Research Association, Chicago.

[4] Fosnot C. T. and Dolk Maarten. 2002. Young Mathematicians at Work: Constructing Fractions, Decimal, and Percents. Portsmouth: Heinemann.

[5] Hadi Sutarto. 2002. Effective Teacher Professional Development For The 
Implementation of Realistic Mathematics Education in Indonesia. Doctoral Dissertation, University of Twente.

[6] Johnson, Elaine B. 2010. CTL (Contextual Teaching and Learning) menjadikan kegiatan belajar-mengajar mengasyikkan dan bermakna. Bandung: Kaifa.

[7] Julie, Hongki. 2014. Student Learning Materials on The Multiplication and Division of Fractions for Grade Five With Realistic Mathematics Education. Proceeding The $3^{\text {rd }}$ SEA-DR Conference.

[8] Julie, Hongki. 2016. Developing Student Learning Materials on The Multiplication Fractions For Grade Five With Realistic Mathematics Education. Presented on Fourth SEA - DR Conference.

[9] Kandarkis, A. G. dan Poulos, M. S. 2008. Teaching Implications of Information Processing Theory and Evaluation Approach of Learning Strategies Using LVQ Neural Network. Advances in Engineering Education, Issue 3, Volume 5, March 2005.

[10] Lortie-Forgues, H., Tian, J., \& Siegler, R. S. 2015. Why is learning fraction and decimal arithmetic so difficult? Developmental Review. In press.

[11] Ma, L. 1999. Knowing and teaching elementary mathematics: Teachers' understanding of fundamental mathematics in China and the United States. Mahwah, NJ: Lawrence Erlbaum Associates.

[12] Magnusson, S., Krajcik, J., \& Borko, H. 1999. Nature, sources, and development of pedagogical content knowledge for science teaching. In J. Gess-Newsome \& N. G. Lederman (Eds.), Examining pedagogical content knowledge: The construct and its implications for science education (pp. 95-132). The Netherlands: Kluwer Academic Publishers.

[13] Marks, R. 1990. Pedagogical content knowledge: From a mathematical case to a modified conception. Journal of Teacher Education, 41(3), 3-11.

[14] Marpaung, Y. 1987. Sumbangan Pikiran terhadap Pendidikan Matematika dan Fisika. Yogyakarta: Pusat Penelitian Pendidikan Matematika/Informatika.

[15] Matlin, Margaret W. 2009. Cognition. Seventh Edition. New York: John Wiley\&Sons, Inc.

[16] Merriam, S. B. 2009. Qualitative Research: A Guide to Design and Implementation. San Francisco: Jossey Bass A Wiley Imprint.

[17] Miles, M. B. dan Huberman, A. M.. 1994. Qualitative Data Analysis. London: Sage Publications.

[18] Morra, Sergio dkk. 2008. Cognitive Development: Neo-Piagetian Perspectives. New York: Lawrence Erlbaum Associates.

[19] Paul Suparno. 1997. Filsafat Konstruktivisme dalam Pendidikan. Yogyakarta: Penerbit Kanisius.

[20] Paul Suparno. 2001. Teori Perkembangan Kognitif Jean Piaget. Yogyakarta: Penerbit Kanisius.

[21] Scheerer, Constance (editor). 1964. Cognition: Theory, Research, Promise. New York: Harper\&Row Publishers. 
[22] Shanty, Nenden Octavarulia, Yusuf Hartono, Ratu Ilma Indra Putri, \& Dede de Haan. Design Research on Mathematics Education: Investigating The Progress of Indonesian Fifth Grade Student' Learning on Multiplication of Fractions With Natural Numbers. IndoMS Journal Mathematics Education, 2, 147-162.

[23] Shulman, L.S. 1986. Those who undersand: Knowledge growth in teaching, educational researcher, 15 (2), 4-14.

[24] Shulman, L.S. 1987. Knowledge and teaching: Foundation of the new reform. Harvard Educational Review, 57 (1), 1-22.

[25] Skemp, Richard R. 2009. Psychology of Learning Mathematics. New York: Routledge Taylor \& Francis Group.

[26] Solso. 1991. Cognitive Psychology. Boston: Allyn and Bacon.

[27] Suharnan. 2005. Psikologi Kognitif. Surabaya: Penerbit Srikandi.

[28] Treffers, A. (1991). Didactical background of a mathematics program for primary education. In L. Steefland (Ed.), Realistic mathematics education in primary school (pp. 21-56). Utrecht: CD- $\beta$ Press. 